\title{
IMPLICATION OF PERIO IN FORENSIC ODONTOLOGY
}

\section{Dr. Mahesh G. Chavda}

\section{Dr. Neeta V.} Bhavsar

\section{Dr. Mahendra} Kumar Singh*
Professor Govt. Dental College Ahmedabad

Professor \& HOD Govt. Dental College Ahmedabad

Post Graduate Student Govt. Dental College Ahmedabad *Corresponding Author

\section{ABSTRACT}

Forensic research pertaining to dentistry has taken several turns and reached a crossroad where every separate branch has an entity to contribute to support identification of the deceased. Periodontics is utilized for identification of individuals through morphology and pathology of periodontium and is also utilized for age estimation studies which include periodontal ligament attachment level, root transparency and root length. The prime focus of this literature is to highlight how a periodontist can contribute to the field of forensic odontology by associating the following parameters of his domain, to unravel a crime scene. This literature aims to summarize the findings of studies that reported periodontal associations or potential associations that could play a role in forensic research.

\section{KEYWORDS : Implication, Forensic research , Periodontics , Forensic odontology}

\section{INTRODUCTION}

To reach the depth of the criminal investigation, combined efforts of a multidisciplinary team are required. The report presented by a forensic expert plays a crucial role in the conviction of a criminal. This makes it evident why he/she must be precise, methodical, elaborative and foremost, unbiased. The science of using oral structures for human identification, better known as forensic odontology, is a special branch of forensic medicine. It is performed by a comparative evaluation of the antemortem and postmortem records.

The first ever case that recorded the use of dental identification was that of John Talbot, who fell in the Battle of Castillion in 1453. Dr. Paul Revere, who identified the body of Dr. Joseph Warren, a revolutionary in 1775 by identifying the silver and ivory bridge he had constructed for the latter, 2 years prior was the first forensic odontologist. The first comprehensive text on forensic odontology entitled, "L' Art Dentaire en Medicine Leagale" was published by Dr. Oscar Amoedo, who is also known as the father of forensic odontology.

There exists a protocol which the forensic odontologist abides by for dental identification. First, a comparative identification to conclude that the dental remains of the deceased and antemortem details belong to the same individual is performed. In case, there is no enough antemortem record; an elaborate postmortem record also known as "dental profiling" is conducted so as to match whatever scarce antemortem material is available.[1]

Forensic research pertaining to dentistry has taken several turns and reached a crossroad where every separate branch has an entity to contribute to support identification of the deceased.[2] Periodontics is clinical dental speciality dealing with diseases of periodontium. [3] This speciality is utilized for identification of individuals through morphology and pathology of periodontium and is also utilized for age estimation studies which include periodontal ligament attachment level, root transparency and root length..$^{[4,5]}$

The prime focus of this literature is to highlight how a periodontist can contribute to the field of forensic odontology by associating the following parameters of his domain, to unravel a crime scene. This literature aims to summarize the findings of studies that reported periodontal associations or potential associations that could play a role in forensic research.

\section{METHOD OF DATA ACQUISITION}

A PubMed search was conducted using the keywords "forensic dentistry," "cementum annulations," "dental implants," DNA analysis", " identification", "gender determination ," age estimation ",to identify articles published until June 2020. A plausible link / association between forensic odontology and periodontology was sought for and all important facts were compiled to formulate this review.

\section{APPLICATION OF PERIODONTAL KNOWLEDGE TO FORENSIC DENTISTRY}

Forensic odontology has been designated as a crucial part of forensic medicine. The first ever evidence of the use of forensic odontology to identify a dead subject was done in the late 60's $\mathrm{AD}$ when King Nero recognized the lady through her peculiar teethsetting. [6] Periodontology can be utilized for identification of individuals through morphology and pathology of periodontium and is also utilized for age estimation studies which include (periodontal ligament attachment level) periodontosis, root transparency and root length.[7] The study of the periodontal structures post mortem can help in :

I. Identification of the deceased.

II. Determination of the time of death .

III. Sex determination \&

IV. Age estimation of the deceased.

\section{IDENTIFICATION}

The central dogma of dental identification is that postmortem dental remains can be compared with antemortem dental records, including written notes, study casts, radiographs etc, to confirm identity. Clearly, individuals with numerous and complex dental treatments are often easier to identify than those individuals with little or no restorative treatment.[8] The forensic dentist produces the postmortem record by careful charting and written descriptions of the dental structures and radiographs. If the antemortem records are available at this time; postmortem radiographs should be taken to replicate the type and angle of these structures which are examined during the comparative dental identification, particularly in 
those instances in which restorative treatment is absent or minimal. ${ }^{[9]}$

Periodontics is the speciality of dentistry dealing with diseases of the gums and other structures around the teeth.[3] This speciality is utilized for identification of individuals through gingival morphology and pathology, periodontal ligament morphology and pathology, status of alveolar bone and periodontal cosmetic surgeries, implants .

Interrelationship of Periodontics \& Implants with forensic odontology ${ }^{55,58}$

\section{Gingival morphology and pathology :}

a. Contour, recession, focal/diffuse, enlargements, interproximal craters

b. Colour :- inflammatory changes, physiological (racial) or pathological

pigmentations

c. Calculus deposits

Periodontal ligament morphology and pathology :

a. Thickness

b. Widening

c. Lateral periodontal cysts

\section{Alveolar process and lamina dura :}

a. Height, contour, density of crestal bone

b. Thickness of interradicular bone

c. Exostoses, tori

d. Pattern of lamina dura

e. Bone loss (horizontal/vertical)

f. Trabecular bone pattern of bone

g. Residual root fragments

\section{Periodontal cosmetic surgeries :}

a. Crown lengthening procedure

b. Root hemisection along with regenerative surgery

c. Periodontal microsurgery

\section{Implants :}

Apart from the various periodontal aspects that aid forensic researchers, use of implants for the same is the most recently acknowledged innovation. Although dental implants lack individuality, they have an advantage of being corrosion resistant and having a high melting point.Extreme heat causes central vaporization of pulp tissues leading to disintegration and separation of the tooth crown and root. Unlike the conventional restorative materials such as dental amalgam, composite resin, and gold which may melt or distort in high temperatures, titanium and its alloys which is commonly used to manufacture dental implants has a melting point above $1650^{\circ} \mathrm{C}$ which helps them sustain thermal insults. While titanium may not melt at high temperature, they may 'sag'; a slight warping of the object's shape. These properties of implants have shown to give them added importance for playing evidence in victim identification. ${ }^{[2]}$

Pre and post-incineration imaging of the laser etched batch number on the implant body, using a microscope attached with a digital camera, showed that the batch number was persistent even after the implant was subjected to high temperature. The presence of the batch number postfiring was dependent on the depth of etching and the presence of the oxidation layer on the implant surface. This unique concept could be utilized by implant manufacturers in labelling their implants which could help suffice the goal of victim identification.

\section{Implant Recognition Software}

One of the latest innovations is an implant recognition software developed by G. Michelinakis, consisting of a database fed with a set of questions that determine the different implant systems. In addition, radiographic and clinical images of the implant systems are also provided in the software database. At the end of the search, complete manufacturing details are revealed that can aid in case recognition and simplifies the job of a forensic odontologist. [10]

\section{DETERMINATION OF TIME OF DEATH BY - GINGIVAL TISSUES}

The post mortem interval (PMI) is the amount of time that has elapsed since the time of death, and its determination has always been a fundamental issue in the forensic field. In standard forensic practice, PMI is usually estimated by assessing the evidence provided by the body itself, including the temperature, muscular and neuro-muscular reactivity, post mortem lividity, autolysis, putrefaction and fluid biochemistry, as well as environmental markers. However, PMI estimation remains controversial, and it is often not possible to draw any definite conclusions concerning the time of death based on the appearance of a single post mortem change. ${ }^{[1]}$

Many different approaches have been explored in recent years, and the literature is constantly expanded by newer strategies that are being considered as additional support so that a more accurate value can be provided by using a combination of different methods.[12] Over the decades, histological and immunohistochemical analysis of different post mortem tissues have become increasingly important, as they might provide additional hints that may be useful in determining the time interval after death.

Although there are various methods adopted to estimate the PMI, newer methods are being investigated as an additional aid so that a combination of different methods can give a accurate value. And one such method is the use of gingival tissue in estimation of time since death.Various changes are studied to determine the post mortem interval such as :

a) Histological changes

b) Ultrastructural changes

c) Electrolyte changes

d) Immunohistochemical distribution and mRNA expression of hypoxia inducible factor (HIF-lalpha)

A study was conducted to demonstrate the features of decomposition at the cellular level in post-mortem gingival tissues at different time intervals after death and observe the cellular changes in the unfixed antemortem gingival tissue at regular time intervals. They conclude that there was a significant association between the time intervals and degenerative changes. The initiation of the decomposition process at the cellular level begins within 10 hours after death and the other clinical features of decomposition occur subsequently. ${ }^{[12]}$

Another study was done to evaluate the histological and ultrastructural changes in the gingival tissue along with the changes in electrolyte levels (sodium, potassium, calcium, and magnesium) among the three groups which included normal, $2 \mathrm{hr}$, and $4 \mathrm{hr}$ since death. Result shows that the light microscopic changes were observed as early as $2 \mathrm{hr}$ since death, but there was no significant difference observed between $2 \mathrm{hr}$ and $4 \mathrm{hr}$ postmortem samples whereas ultrastructurally significant difference in morphology was observed between $2 \mathrm{hr}$ and $4 \mathrm{hr}$ postmortem gingival tissue. ${ }^{[13]}$

There is a paucity of information in the literature in relation to the decomposition of oral tissues. As a consequence this can place restraints on the role of forensic pathologists to estimate the time of death. Although there are many methods available to estimate the time of death, none is reliable enough by itself 
as a "stand alone" method because of the inevitable influence of unpredictable external factors. In this context the changes that occur post-mortem in human gingival tissues would appear to be useful method to estimate the time of death in the early PMI (0-24 hrs).

\section{SEX DETERMINATION}

Isolation of Epithelial cells from Tooth Brush and Gender Identification Vikram Simha A Reddy [15] determines the importance of tooth brush from which DNA can be isolated and used for sex determination in forensic analysis. The epithelial cells adhered to the bristles of tooth brush were collected and genomic DNA was extracted and quantified using Nanodrop 1000 spectrophotometer. Gender identification was done by amplification of sex determining region on $\mathrm{Y}$ chromosome (SRY) gene using real-time polymerase chain reaction and minimal amount of DNA (in pico grams) with $100 \%$ sensitivity and $73.3 \%$ specificity, i.e., all male samples showed positive results and out of 15 female samples 4 showed false positive results, i.e wrongly identified as males. With this study, they conclude that PCR is a valuable and sensitive procedure where minute contamination may cause alteration in the result, i.e, 4 females showed false positive result. Minute amount of DNA in picograms, which was collected at different intervals is enough for amplification of SRY gene and tooth brush can be used as one of the very valuable sources of gender identification.

\section{Role of Dental Calculus in Gender Determination}

Dental calculus is used for determination of sex by the PCR method using primers, which recognize DYZ3 region of Ychromosome and DXZl of $\mathrm{X}$ - chromosome. The minimum amount of DNA for sex determination was $3 \mathrm{pg}$. Sex determination using DNA in dental calculus will be quite useful for forensic application because it can be done without destruction of morphological characteristics of the teeth.[16]

\section{AGE ESTIMATION}

\section{CEMENTUM : A MARKER FOR AGE ESTIMATION}

Age estimation is an important criterion in the identification process when very less information about the deceased is available. Cementum is a connective tissue and part of the periodontium that surrounds the tooth and is deposited throughout life. Deposition occurs in the form of concentric incremental lines and each line corresponds to 1 year of life. Contemporary reports have shown that tooth cementum annulations (TCAs) are a reliable source as compared to other human morphological or histological traits for age estimation.[17] A longitudinal ground section of a tooth mounted on a microscope is used to assess the alternate light and dark bands at the apical and middle third of the root, which are counted on a pictomicrograph. Examination can be done under light microscopy, polarized microscopy, or phasecontrast microscopy. ${ }^{[19]}$

Number of incremental lines $(\mathrm{n})=\mathrm{X} / \mathrm{Y}$ where,

$\mathrm{X}=$ Total width of cementum from dentino-cementum junction to cementum surface.

$\mathrm{Y}=$ Width of cementum between two adjacent incremental lines.

Addition of the eruption age of the tooth with the number of lines can give us the age of the individual. However, to assure a high reliability of the method, TCAs diagnosis has to be based on several teeth of one individual if possible and needs to be supported by different techniques in forensic cases.[19] Dental cementum is laid down in alternating opaque and translucent bands representing winter (dormant) and summer (growth) seasons. Wedel in 2007 had a vision that if the timing of the transition between winter and summer bands could be identified in humans, dental cementum increment analysis (DCIA) could be used to specify the season at death. Hence, through his pilot study, the former stated that a transition from translucent to opaque bands was observed in teeth extracted in early October while teeth extracted in early April showed nascent translucent bands. Further, significant correlations were observed between band thickness and number of days into either season, suggesting that bandwidth increases as either season progresses. Hence, he was successful in providing a resource to forensic anthropologists for determining the season at death through DCIA. ${ }^{[20]}$

P. E. M Dias in 2010[21] evaluate age estimation from dental cementum incremental lines and periodontal disease and check the influence of periodontal disease on age, estimates by analyzing both the number of cementum lines and the correlation between cementum thickness and actual age on freshly extracted teeth. There was moderate correlation $((r)=0.58)$ for the entire sample, with mean error of 9.7 years. For teeth with periodontal pathologies, correlation was 0.03 with a mean error of 22.6 years. For teeth without periodontal pathologies, correlation was 0.74 with mean error of 1.6 years. There was correlation of 0.69 between cementum thickness and known age for the entire sample, 0.25 for teeth with periodontal problems and 0.75 for teeth without periodontal pathologies. The technique was reliable for periodontally sound teeth, but not for periodontally diseased teeth.

\section{PERIODONTAL LIGAMENT : A MARKER FOR AGE ESTIMATION}

Catarina-Dourado Sequeira in 2014[21] done age estimation using the radiographic visibility of the periodontal ligament in lower third molars in a Portuguese population. Periodontal ligament visibility was assessed in the lower third molars, using a sample of 487 orthopantomograms, 228 of which belonging to females and 259 to males, from a Portuguese population aged 17 to 3 lyears. A classification of four stages based on the visual phenomenon of disappearance of the periodontal ligament of fully mineralized third molars was used. For each stage $(0,1,2,3)$ median, variance, minimal and maximal age were assessed. The relationship between age and stage of periodontal ligament had a statistical significance for both sexes. In this population, stage 3 can be used to state that a male person is over 21 years-old; for females, another marker should be used. This technique can be useful for determining age over 21 , particularly in males.

\section{CONCLUSION}

Forensic odontology is an important upcoming and expanding field of dentistry, which is practiced worldwide. The identification of a person in various situations is very important, by which the culprit in criminal cases could be identified and assist judicial proceedings and obtaining justice. Forensic odontologist identifies a person by determining sex and age, using various tissues \& techniques, including that of gingiva, and from dental records. This literature review compilation has tried to provide inputs from the field of periodontology that could possibly promote forensic research by their methodical approach. It helps us understand that like specialists from other dental fields, even a periodontist can make valuable contributions to forensic odontology and can also actively take part in probable and possible identification of a known and unknown individual before and after death.

\section{REFERENCES}

1. Ranganathan K, Rooban T, Lakshminarayan V. Forensic odontology: A review. J Forensic Odontol.2009; 1:42-4.

. Gattani DR, Deotale SP. Forensic dentistry: Adding a perio'scope'to it!. Journal of Indian Society of Periodontology 2016 Sep;20(5):485.

3. Shamim T. Forensic odontology. J Coll Physicians Surg Pak 2012;22:240-5.

4. Shamim T. Publication trends in the journal of forensic dental sciences 20092012. J Sci Res 2013;2:152-6.

5. Shamim T. Periodontics perspective in identification and age estimation. Eur Forensic Sci Oct-Dec. 2014;1(1):19 
6. Sansare K. Forensic odontology, historical perspective. Indian J Dent Res.1995;6:55-7

7. Shamim T. A new working classification proposed for forensicodontology.J Coll Physicians Surg Pak 2011;21:59

8. Sweet D, DiZinno J A. Personal identification through dental evidence-tooth fragments to DNA. J Calif Dent Assoc 1996; 24:35-42.

9. Goldstein M, Sweet D J, Wood R E. A specimen-positioning device for dental radiographic identification. Image geometry considerations. J Forensic Sci $1998 ; 43: 185-189$

10. Michelinakis G, Sharrock A, Barclay CW. Identification of dental implants through the use of Implant Recognition Software (IRS) Int Dent J. 2006;56:203-8

11. Madea B. Methods for determining time of death. Forensic science, medicine, and pathology. 2016 Dec 1;12(4):451-85.

12. Henssge C, Madea B. Estimation of the time since death in the early postmortem period. Forensic Sci Int. 2004;144(2-3):167-175.

13. Pradeep GL, Uma K, Sharada P, Prakash N. Histological assessment of cellular changes in gingival epithelium in ante-mortem and post-mortem specimens. Journal of Forensic Dental Sciences. 2009 Jul 1; l(2):61.

14. Muthukrishnan S, Narasimhan M, Paranthaman SK, Hari T, Viswanathan $P$ Rajan ST. Estimation of time since death based on light microscopic, electron microscopic, and electrolyte analysis in the gingival tissue. Journal of forensic dental sciences. 2018 Jan; 10(1):34.

15. Reddy VS, Sriram G, Saraswathi TR, Sivapathasundharam B. Isolation of epithelial cells from tooth brush and gender identification by amplification of SRY gene. Journal of forensic dental sciences. 2011 Jan;3(1):27.

16. Smith T, Brownlees L. Age Assessment Practices: A Literature Review \& Annotated Bibliography. New York: United Nations Children's Fund (UNICEF); 2011.

17. Stein TJ, Corcoran JF. Pararadicular cementum deposition as a criterion for age estimation in human beings. Oral Surg Oral Med Oral Pathol. 1994;77:266-70. [PubMed] [Google Scholar]

18. Pundir S, Saxena S, Aggarwal P. Estimation of age based on tooth cementum annulations using three different microscopic methods. J Forensic Dent Sci. 2009;1:82-7. [Google Scholar]

19 Aggarwal P, Saxena S, Bansal P. Incremental lines in root cementum of human teeth: An approach to their role in age estimation using polarizing microscopy. Indian J Dent Res. 2008;19:326-30. [PubMed] [Google Scholar]

20. Wedel VL. Determination of season at death using dental cementum increment analysis. J Forensic Sci. 2007:52:1334-7. [PubMed] [Google Scholar]

21. Dias PE, Beaini TL, Melani RF. Age estimation from dental cementum incremental lines and periodontal disease. J Forensic Odontostomatol. 2010 Dec 1;28(1):13-21.

22. Sequeira CD, Teixeira A, Caldas IM, Afonso A, Pérez-Mongiovi D. Age estimation using the radiographic visibility of the periodontal ligament in lower third molars in a Portuguese population. Journal of clinical and experimental dentistry. 2014Dec;6(5):e546 